\title{
A cross-sectional study assessing the relationship between BMI, asthma, atopy, and eNO among schoolchildren
}

Fabio Cibella, MD*; Giuseppina Cuttitta, MD*; Stefania La Grutta, MD*†; Mario Raphael Melis, MD*; Salvatore Bucchieri, MD*; and Giovanni Viegi, MD*

Background: Increased body weight may influence airway inflammatory mechanisms.

Objective: To assess whether overweight-obesity (OW-O), evaluated as increased body mass index, is associated either with exhaled nitric oxide (eNO), a marker of airway inflammation, or with allergic sensitization in a large sample of children and adolescents.

Methods: A cross-sectional, epidemiological study was performed on a population sample of schoolchildren evaluating 708 subjects (age 10-16 years; BMI 13-39 kg/m²) by respiratory health questionnaire, skin prick tests, spirometry, and eNO measure.

Results: Prevalence rates were: OW-O 16.4\%, asthma ever (A) $11.9 \%$, and rhinoconjunctivitis (RC) $14.8 \%$. Asthma ever and allergic sensitization were significantly more frequent among OW-O (21.0 and 51.6\%) than in non-OW-O (10.2 and 37.0\%, respectively). The forced expiratory volume in 1 second $\left(\mathrm{FEV}_{1}\right)$ /forced vital capacity (FVC) ratio was not significantly different between OW-O and non-OW-O. Exhaled NO (median and interquartile range) was 15.3 (11.2-23.1) ppb in the overall sample, 20.3 (12.9-35.8) ppb among allergic subjects, and $13.9(10.6-18.3) \mathrm{ppb}$ among nonallergic subjects $(P<.0001)$. No significant difference between OW-O and non OW-O subjects was found in eNO levels. Similarly, OW-O subjects with A or RC did not show significantly higher eNO levels than non-OW-O. In a logistic regression model, presence of allergic sensitization, A, and $\mathrm{RC}$, and not OW-O, were significant predictors of increased eNO.

Conclusions: In children, OW-O was not associated with increased eNO levels, but it was an independent risk factor for asthma and allergic sensitization.

\section{INTRODUCTION}

Epidemiological surveys have shown a trend to increasing prevalence of asthma ${ }^{1}$ and obesity ${ }^{2}$ over the last decades. Because both asthma and obesity are characterized by inflammatory processes, mechanisms based on common pathways, such as endocrine factors including adipokines and reproductive hormones, ${ }^{3}$ have been proposed as a plausible explanation for the association between the 2 conditions. ${ }^{4,5}$ In fact, a higher adiposity in infancy has been recently demonstrated to be associated with increased risk of recurrent wheezing during childhood, ${ }^{6}$ and increased body weight may influence airway inflammatory mechanisms, ${ }^{7}$ even though underlying mechanisms have not been completely elucidated. ${ }^{8}$

Affiliations: * National Research Council of Italy, Institute of Biomedicine and Molecular Immunology, Palermo, Italy; $\uparrow$ Health and Environment Unit, Regional Agency for Environment Protection-ARPA Sicilia, Palermo, Italy.

Disclosures: Authors have nothing to disclose.

Funding Sources: This research was fully supported by a grant from Regional Agency for Environment Protection (ARPA Sicilia), DDG No. 303/2005.

Received for publication April 7, 2011; Received in revised form July 29, 2011; Accepted for publication August 5, 2011.

(C) 2011 American College of Allergy, Asthma \& Immunology.

Published by Elsevier Inc. All rights reserved.

doi:10.1016/j.anai.2011.08.001
Ann Allergy Asthma Immunol. 2011;107:330-336.

Exhaled nitric oxide (eNO) is a useful noninvasive marker of airway inflammation, ${ }^{9}$ particularly in children with asthma. ${ }^{10} \mathrm{~A}$ highly significant correlation with blood eosinophilia was found in children with mild to moderate persistent asthma followed by the Childhood Asthma Research and Education Network supported by the National Heart, Lung, and Blood Institute. ${ }^{11}$ Indeed, the interest in eNO is based on the assumptions that eNO is a marker of asthma and asthma control, and that it reflects eosinophilic airway inflammation. However, the literature remains inconclusive. ${ }^{12}$

Few studies have investigated the relationships between body mass index (BMI) and eNO in pediatric populations. In 40 nonatopic children (range, 6-18 years) with no history of respiratory diseases, no relationship was detected between eNO and age- and sex-corrected body mass index. ${ }^{13}$ In addition, when asthma was taken into account, eNO levels did not differ between obese and nonobese asthmatic children. ${ }^{14}$ Similarly, eNO was not correlated to adiposity among adolescents with moderate to severe asthma. ${ }^{15}$

Although allergic sensitization is an important phenotype in children with asthma and a factor able to influence eNO levels per se, ${ }^{16}$ few and controversial data exist on the relationship between obesity and atopy. In fact, an increased BMI was a significant predictor of atopy in children, ${ }^{17}$ but only in girls. Conversely, no association was found between BMI and self-reported allergy in a large Italian population sample. ${ }^{18}$ 
Similarly, no independent relationship between BMI and atopy-as assessed by skin prick tests-was found in US children. ${ }^{19}$

Thus, the association of increased body weight with allergic sensitization, elevated eNO, and asthma symptoms is controversial. These factors-body weight, eNO, allergic sensitization, and asthma symptoms - have not been evaluated simultaneously from a general population sample of older children.

The aim of our cross-sectional study was to assess whether overweight-obesity (OW-O) per se is associated with higher exhaled nitric oxide or increased prevalence of allergic sensitization and asthma in a large sample of schoolchildren aged 10 to 16 years, investigated by means of questionnaires, spirometry, and skin prick tests.

\section{METHODS}

\section{Patient Population}

This cross-sectional study was carried out in a general population sample of 10- to 16-year-old schoolchildren from 16 schools selected on the basis of their geographical distribution among the 59 junior high schools of Palermo $(680,000$ inhabitants), Southern Italy, during November 2005 to May 2006. The entire student population of the 16 schools was 9,922 children. From this group, we randomly selected 2,481 children (1 of every 4 ). Three hundred three children did not obtain parental consent or were not present at school in the day of the study. Thus 2,178 children completed a respiratory health questionnaire and underwent lung function testing and skin prick test (SPT) at school. Among them, 28 children refused SPT or were not able to perform a valid spirometry. Finally, 2,150 children were completely evaluated by questionnaire, lung function testing, and SPT at school.

Except for asthma, no other chronic pulmonary disease was reported.

\section{Study Parameters}

Following the Italian SIDRIA Study (Studio Italiano Disturbi Respiratori Infanzia e Ambiente), ${ }^{20}$ which, in turn, adopted the standardized method of the International Study of Athma and Allergies in Childhood, ${ }^{21}$ a child's history of "asthma ever" was defined as a positive answer to the question "Have you ever had asthma?" Rhinoconjunctivitis was defined as a positive answer to both the questions "Have you ever had a problem with sneezing, or runny, or blocked nose apart from common cold or flu in the last 12 months?" and "In the past 12 months, has this nose problem been accompanied by itching and/or watering eyes?" For the analyses, 3 subgroups were considered: patients with asthma, regardless of the presence of rhinoconjunctivitis (A); subjects with rhinoconjunctivitis (RC); and subjects without asthma or RC (nAnRC). Consequently, individuals with both asthma and rhinoconjunctivitis were classified as $\mathrm{A}$, whereas $\mathrm{RC}$ included only subjects with rhinoconjunctivitis alone.

Skin prick tests were performed according to European Academy of Allergy and Clinical Immunology recommenda- tions $^{22}$ with a standard panel including Dermatophagoides mix, grass mix, Parietaria judaica, olive, dog and cat dander, Alternaria alternata, and Blattella germanica, plus a positive (histamine 1\%) and a negative (saline) control (Stallergènes Italia S.r.l., Milan, Italy). The reading was performed after 15 minutes: reactions were considered positive if the mean wheal diameter (computed as the maximum diameter plus its orthogonal divided by 2) was $3 \mathrm{~mm}$ or larger, after having subtracted the wheal diameter of the reaction to the negative control. Allergic sensitization was defined as the presence of at least 1 positive skin prick test.

Height and weight were measured in all of the children in standing position without shoes, using a stadiometer and an electronic digital scale: BMI was computed as weight/height ${ }^{2}$ $\left(\mathrm{kg} / \mathrm{m}^{2}\right)$. Overweight-obese children were defined as BMI larger than the age- and sex-specific $85^{\text {th }}$ percentiles of the studied population sample. ${ }^{23}$

Pulmonary function tests were performed by a portable spirometer (MicroLoop, Micro Medical, Chatham Maritime, Kent, United Kingdom). Forced expiratory volume in $1 \mathrm{sec}-$ ond $\left(\mathrm{FEV}_{1}\right)$, forced vital capacity (FVC) and maximum midexpiratory flow $\left(\mathrm{FEF}_{25-75 \%}\right)$ were measured according to American Thoracic Society and European Respiratory Society guidelines: The best FVC and $\mathrm{FEV}_{1}$ were retained, and $\mathrm{FEF}_{25-75 \%}$ was selected from the maneuver with the largest sum of $\mathrm{FEV}_{1}$ and $\mathrm{FVC}^{24}$ The $\mathrm{FEV}_{1} / \mathrm{FVC} \%$ ratio was computed as best $\mathrm{FEV}_{1}$ /best FVC. Spirometric predicted values were those from Pistelli et al., ${ }^{25}$ derived from an Italian population sample. An impaired pulmonary function was defined when $\mathrm{FEV}_{1} / \mathrm{FVC} \%$ was below the $5^{\text {th }}$ percentile of its normal distribution ( $87 \%$ of predicted for boys and $90 \%$ for girls)..$^{25}$

\section{Nitric Oxide Measurements}

Because we could not study the entire sample by eNO analysis, because of resources limitations, among 2,150 subjects who completed the baseline evaluation, 717 children were randomly selected (one every three subjects) and evaluated by off-line eNO measurements using single exhalations with constant flow by a dynamic-flow restrictor following American Thoracic Society and the European Respiratory Society recommendations. ${ }^{26}$ The exhaled gas was collected into NOinert 4-L mylar bags ${ }^{27}$ and analyzed within 4 hours by a chemiluminescence analyzer connected to a computerized system (NIOX, Aerocrine AB, Stockholm, Sweden). The instrument had a sensitivity of 1.5 part per billion (ppb), a detection range of 0 to $200 \mathrm{ppb}$, and a response time of less than $0.8 \mathrm{~s}$, and was calibrated with a certified NO gas mixture. Finally, 9 individuals were not able to perform a valid maneuver; thus, 708 children had eNO data were available for the analysis.

The study was approved by the Institutional Review Board of the University Hospitals of Palermo, and all children had a written informed consent signed by a parent. The respect of individual privacy concerning clinical data was granted according to the Italian law. 


\section{Statistical Analyses}

One-way and two-way analysis of variance (ANOVA) and frequency distribution tables $\left(\chi^{2}\right)$ for parametric variables were performed: because the distribution of eNO values was highly skewed, analysis was performed after natural log transformation (ln eNO). Nonparametric Mann-Whitney $U$ test was used when appropriate. To study the independent variables able to influence the risk for elevated eNO levels, eNO was dichotomized at the level of its $75^{\text {th }}$ percentile, and a logistic regression model was used to explore the relationships between the dependent variable (eNO) and independent variables (BMI, impaired lung function, atopy, presence of asthma, or rhinitis), adjusting for sex. Odds ratios with corresponding $95 \%$ confidence intervals (CI) were calculated for all predictors. All computations were performed by StatView statistical software package (SAS Institute, Cary, North Carolina). A probability level of $P<.05$ was selected as being statistically significant.

\section{RESULTS}

The 708 subjects who performed eNO measurements (352 males, $49.7 \%$ ) were not significantly different compared with the whole population sample $(N=2,150)$ as concerns age, sex, allergic sensitization, BMI, symptoms, and lung function (Table 1). One hundred sixteen (16.4\%) overweight-obese subjects $(\mathrm{OW}-\mathrm{O})$ were included, with no significant difference by sex $\left(P=.10, \chi^{2}\right), 84(11.9 \%)$ subjects with $\mathrm{A}, 105$ (14.8\%) with RC, and $519(73.3 \%)$ nAnRC.

Percent predicted $\mathrm{FEV}_{1} / \mathrm{FVC}$ ratio was significantly reduced among A subjects $(97.5 \pm 7.7 \%)$ compared with both $\mathrm{RC}(100.4 \pm 7.0 \%, P=.002)$ and nAnRC $(101.1 \pm 6.3 \%$, $P<.0001$ ) by ANOVA. Similarly, $\mathrm{FEF}_{25 / 75 \%}$ (\% pred) was lower in A $(76.1 \pm 19.7 \%)$ compared with RC $(84.5 \pm 20.4$, $P<.002)$ and nAnRC $(85.5 \pm 18.6, P<.0001)$. No significant difference was found for both $\mathrm{FEV}_{1} / \mathrm{FVC}$ and $\mathrm{FEF}_{25 / 75 \%}$ between $\mathrm{nAnRC}$ and RC.

Prevalence rates of $\mathrm{A}$ and allergic sensitization were significantly higher in OW-O than in non-OW-O ( $\chi^{2}$, Table 2$)$.
Percent predicted $\mathrm{FEV}_{1}$ and FVC were significantly lower in OW-O than non-OW-O, whereas no significant difference was found for $\mathrm{FEV}_{1} / \mathrm{FVC}$ and $\mathrm{FEF}_{25-75 \%}$ (percent predicted) (Table 2).

Exhaled nitric oxide (median and interquartile range) was $15.3(11.2-23.1) \mathrm{ppb}$ in the study population, with no significant difference between OW-O (15.0 [11.6-22.3] ppb) and non-OW-O subjects (15.5 [11.2-23.3] ppb) $(P=.87$, MannWhitney $U$-test, Table 2). Similarly, obesity was not associated with increased eNO in A, RC, and nAnRC subgroups compared with nonobese (Mann-Whitney $U$-test, Table 3A). Moreover, no difference was found in distribution of subjects with allergic sensitization between $\mathrm{OW}-\mathrm{O}$ and non-OW-O in both $\mathrm{A}$ and RC subgroups (Table 3B).

In a two-way ANOVA model, allergic sensitization but not OW-O was associated with a significant increase of eNO (Fig 1). In fact, exhaled nitric oxide (median and interquartile range) was $20.3(12.9-35.8)$ ppb among subjects with positive SPT and 13.9 (10.6-18.3) ppb among subjects without positive SPT $(P<.0001$, ANOVA, after natural log transformation). When the combination of asthma ever and allergic sensitization was taken into account, eNO was not significantly more elevated in OW-O children (Fig 2).

When evaluated in different logistic models, OW-O was a significant risk factor for both A (Table 4) and allergic sensitization (Table 5). By a logistic regression model, presence of allergic sensitization, asthma ever, and rhinoconjunctivitis were significant predictors of increased eNO. In the same model, neither OW-O nor impaired lung function were significant risk factors for increased eNO (Table 6).

\section{DISCUSSION}

In this cross-sectional study of schoolchildren, aged 10 to 16 years, no evidence of eosinophilic airway inflammation, as evaluated through exhaled nitric oxide measurements, was found in overweight-obese children. Nevertheless, we confirmed that OW-O was associated with asthma ever and allergic sensitization (Fig 3). Moreover, asthma, rhinocon-

Table 1. Descriptive Data of the Total Sample and Study Population

\begin{tabular}{|c|c|c|}
\hline & Total population sample & Study population \\
\hline Subject (No.) & 2,150 & 708 \\
\hline Males (No., \%) & $1,057(49.2)$ & $352(49.7)$ \\
\hline Age, yrs (mean, range) & $12.6(10-18)$ & $12.6(10-16)$ \\
\hline Asthmatics (No., \%) & $259(12.0)$ & $84(11.9)$ \\
\hline Rhinoconjunctivitis (No., \%) & $326(15.2)$ & $105(14.8)$ \\
\hline Allergic sensitization (No., \%) & $839(39.2)$ & $280(39.5)$ \\
\hline FVC \%pred (mean \pm SD) & $92.2 \pm 11.8$ & $91.5 \pm 11.4$ \\
\hline $\mathrm{FEV}_{1} \%$ pred (mean $\left.\pm \mathrm{SD}\right)$ & $90.3 \pm 11.4$ & $89.7 \pm 11.1$ \\
\hline $\mathrm{FEF}_{25 / 75 \%} \%$ pred (mean $\pm \mathrm{SD}$ ) & $84.8 \pm 19.1$ & $84.2 \pm 19.2$ \\
\hline $\mathrm{FEV}_{1} / \mathrm{FVC} \%$ pred (mean $\pm \mathrm{SD}$ ) & $100.5 \pm 6.5$ & $100.6 \pm 6.7$ \\
\hline Impaired lung function (No., \%) & $90(4.2)$ & $31(4.3)$ \\
\hline $\mathrm{BMI}\left(\mathrm{kg} / \mathrm{m}^{2}\right.$, mean $\left.\pm \mathrm{SD}\right)$ & $21.3 \pm 4.3$ & $21.4 \pm 4.5$ \\
\hline Overweight-obese children (No., \%) ${ }^{a}$ & $323(15.0)$ & $116(16.4)$ \\
\hline
\end{tabular}

All the differences were not statistically significant ( $\chi^{2}$ test for categorical variables and ANOVA for continuous variables).

a Overweight-obese children were defined as BMI greater than the age- and sex- specific $85^{\text {th }}$ percentiles of the studied population sample. ${ }^{27}$ 
Table 2. Distribution of allergic sensitization, A, RC, Respiratory Symptoms, and Respiratory Function in Non-Overweight-Obese (Non OW-O) and Overweight-Obese (OW-O) Subgroups

\begin{tabular}{|c|c|c|c|}
\hline & Non OW-O ( $\mathrm{N}=592)$ & OW-O (N = 116) & $\boldsymbol{P}$ \\
\hline A (No., \%) & $61(10.3)$ & $24(21.0)$ & $.0008^{a}$ \\
\hline RC (No., \%) & $117(19.7)$ & $21(17.7)$ & $.61^{\mathrm{a}}$ \\
\hline FVC \%pred (mean \pm SD) & $92.3 \pm 11.3$ & $87.5 \pm 11.1$ & $<.0001^{b}$ \\
\hline $\mathrm{FEV}_{1} \%$ pred (mean $\left.\pm \mathrm{SD}\right)$ & $90.1 \pm 11.2$ & $87.8 \pm 10.4$ & $.03^{b}$ \\
\hline $\mathrm{FEV}_{1} / \mathrm{FVC} \%$ pred (mean $\pm \mathrm{SD}$ ) & $100.5 \pm 6.5$ & $101.2 \pm 7.8$ & $.27^{\mathrm{b}}$ \\
\hline $\mathrm{FEF}_{25 / 75 \%} \%$ pred (mean $\left.\pm \mathrm{SD}\right)$ & $84.4 \pm 19.1$ & $82.9 \pm 19.8$ & $.42^{\mathrm{b}}$ \\
\hline Allergic sensitization (No., \%) & $219(37.0)$ & $60(51.6)$ & $.0023^{a}$ \\
\hline eNO (ppb, median and interquartile range) & $15.5(11.2-23.3)$ & $15.0(11.6-22.3)$ & $.87^{c}$ \\
\hline
\end{tabular}

A, asthmatic subjects; $\mathrm{RC}$, subjects with rhinoconjunctivitis.

${ }^{a} \chi^{2}$ test.

b One-way ANOVA.

${ }^{c}$ Mann-Whitney U-test.

Table 3. Exhaled NO Levels (A) and Distribution of Subjects with Allergic Sensitization (B) Separately for Overweight-Obese (OW-O) and NonObese Subjects (Non OW-O), in Asthmatic, Rhinoconjunctivitis, and Control (Normal - nAnRC) Subgroups

\begin{tabular}{|c|c|c|c|}
\hline A-Exhaled NO levels & Non OW-O & OW-O & $P^{a}$ \\
\hline nAnRC subjects (ppb, median and interquartile range) & $15.0(11.1-20.7)$ & $13.3(11.4-19.6)$ & .48 \\
\hline Rhinoconjunctivitis ( $\mathrm{ppb}$, median and interquartile range) & $16.1(10.9-26.7)$ & $18.3(11.4-28.7)$ & .72 \\
\hline Asthmatics (ppb, median and interquartile range) & $22.4(12.6-44.2)$ & $17.4(13.5-27.6)$ & .44 \\
\hline
\end{tabular}

a Mann-Whitney U-test.

\begin{tabular}{lccc}
\hline B-Subjects with allergic sensitization & Non OW-O & OW-O & $\boldsymbol{P}^{\mathbf{b}}$ \\
\hline nAnRC subjects (\%) & 33.1 & 47.6 & .01 \\
Rhinoconjunctivitis (\%) & 40.6 & 56.3 & .24 \\
Asthmatics (\%) & 60.0 & 61.5 & .89 \\
\hline
\end{tabular}

${ }^{\mathrm{b}} \chi^{2}$ test.

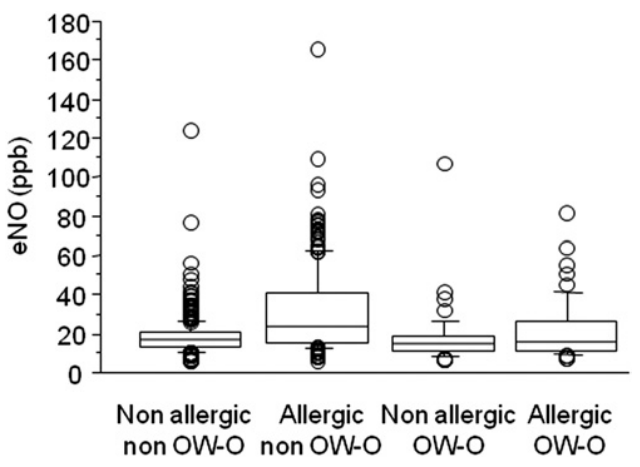

Figure 1. Nitric oxide values for overweight-obese (OW-O) and nonobese (non OW-O) individuals, by presence/absence of allergic sensitization. $P=.17$ for obesity, $P<.0001$ for allergic sensitization, two-way ANOVA, after natural log transformation. Bars indicate (from the bottom to the top) $10^{\text {th }}, 25^{\text {th }}, 50^{\text {th }}$ (median), $75^{\text {th }}$, and $90^{\text {th }}$ percentiles. Values below the $10^{\text {th }}$ and above the $90^{\text {th }}$ percentiles are plotted as circles.

junctivitis, and, mainly, allergic sensitization were independent risk factors for increased eNO levels. No significant effect of pulmonary function on exhaled NO levels was found.

Although BMI is only a proxy for adiposity, ${ }^{28}$ it is easy to measure in epidemiological studies. Because BMI changes

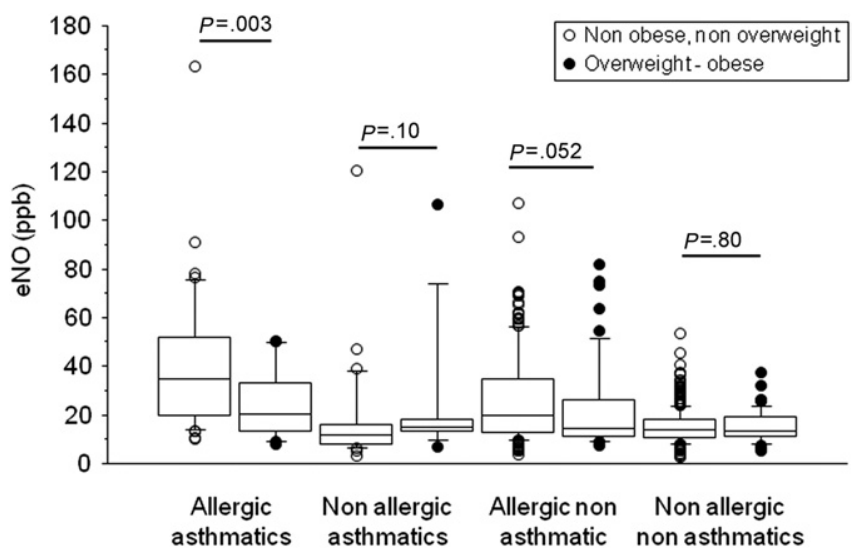

Figure 2. Nitric oxide values for overweight-obese (OW-O) and non-obese (non OW-O) individuals, separately for any combination of presence of asthma ever and allergic sensitization. Two-way ANOVA, after natural log transformation. Bars indicate (from the bottom to the top) $10^{\text {th }}, 25^{\text {th }}, 50^{\text {th }}$ (median), $75^{\text {th }}$, and $90^{\text {th }}$ percentiles. Values below $10^{\text {th }}$ and above $90^{\text {th }}$ percentiles are plotted as circles.

significantly with age and sex in childhood, ${ }^{29}$ overweightobesity cutoff levels were selected according to the age- and sex-related $85^{\text {th }}$ percentiles of the BMI distribution computed on the whole sample. Indeed, a BMI greater than $85^{\text {th }}$ per- 
Table 4. Multiple Logistic Regression Analysis for the Effect of Sex, Parental History of Asthma, Allergic Sensitization, Presence of Rhinoconjunctivitis, and Overweight-Obesity (OW-O) on Asthma Ever

\begin{tabular}{lccc}
\hline & OR & $\mathbf{9 5 \%}$ CI & $\boldsymbol{P}$ \\
\hline Sex (M vs F) & 1.22 & $0.77-1.95$ & .40 \\
Parental history for asthma & 3.36 & $1.90-5.94$ & $<.0001$ \\
Allergic sensitization & 2.22 & $1.39-3.55$ & .0009 \\
Rhinoconjunctivitis & 2.76 & $1.68-4.52$ & $<.0001$ \\
OW-O & 2.23 & $1.32-3.78$ & .0029 \\
\hline
\end{tabular}

Data are expressed as odds ratio (OR) and $95 \%$ confidence interval $(95 \% \mathrm{Cl})$.

Table 5. Multiple Logistic Regression Analysis for the Effect of Overweight-Obesity (OW-O), Presence of Asthma Ever, Rhinoconjunctivitis, and Increased eNO Levels ${ }^{a}$ on Allergic Sensitization

\begin{tabular}{lccc}
\hline & OR & $\mathbf{9 5 \%} \mathbf{C l}$ & $\boldsymbol{P}$ \\
\hline OW-O & 1.89 & $1.24-2.89$ & .003 \\
Sex & 1.52 & $1.10-2.09$ & .012 \\
Asthma ever & 1.74 & $1.04-2.90$ & .034 \\
Increased eNO levels & 5.45 & $3.75-7.91$ & $<.0001$ \\
\hline
\end{tabular}

Data are expressed as odds ratio (OR) and 95\% confidence interval $(95 \% \mathrm{Cl})$ and corrected for impaired lung function and presence of rhinoconjunctivitis.

${ }^{\text {a }}$ Cutoff level at $75^{\text {th }}$ percentile of eNO distribution.

Table 6. Multiple Logistic Regression Analysis for the Effect of Overweight-Obesity (OW-O), Presence of Asthma Ever, Rhinoconjunctivitis, and Allergic Sensitization on Increased eNO Levels $^{\mathrm{a}}$

\begin{tabular}{lccc}
\hline & OR & 95\% Cl & $\boldsymbol{P}$ \\
\hline OW-O & 0.65 & $0.39-1.07$ & .088 \\
Asthma ever & 2.01 & $1.19-3.38$ & .009 \\
Rhinoconjunctivitis & 1.91 & $1.24-2.93$ & .003 \\
Allergic sensitization & 5.45 & $3.75-7.91$ & $<.0001$ \\
\hline
\end{tabular}

Data are expressed as odds ratio (OR) and $95 \%$ confidence interval $(95 \% \mathrm{Cl})$ and corrected for sex and impaired lung function.

a Cutoff level at $75^{\text {th }}$ percentile of eNO distribution.

centile yields an elevated specificity for identifying subjects with increased body fat, ${ }^{30}$ also ensuring a sufficient number of OW-O for statistical comparisons.

The prevalence of OW-O was $16.4 \%$ among our study population. This subgroup showed higher prevalence rates of asthma ever and allergic sensitization. Asthma ever was approximately twofold more frequent among OW-O compared with non-OW-O subjects, in agreement with the results of a recent meta-analysis providing the evidence for the association of asthma and obesity. ${ }^{31}$ However, controversial results exist in children, ${ }^{32,33}$ possibly depending on different approaches to asthma and obesity definitions, muscle mass, or hormone-related differences. ${ }^{34}$

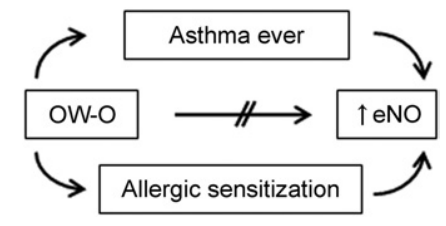

Figure 3. Effect of overweight-obesity (OW-O) on the investigated variables. OW-O was not associated with increased exhaled nitric oxide (eNO) levels, but it was an independent risk factor for asthma ever and allergic sensitization, which, in turn, were independently associated with increased eNO levels.

We found an association between OW-O and asthma in our schoolchildren regardless of sex (Table 4). Conversely, Gilliland et $\mathrm{al}^{23}$ reported an increased risk of new-onset asthma in overweight and obese boys, and Schachter et $\mathrm{al}^{17}$ did not find any association between high BMI and diagnosed or current asthma in 7- to 12-year-old children, in either boys or girls. Different asthma definitions, resulting in different asthma prevalence, and different population samples can account for these controversial results.

Considering airway caliber indicators, OW-O subjects did not show significantly reduced $\mathrm{FEV}_{1} / \mathrm{FVC}$ and $\mathrm{FEF}_{25 / 75 \%}$ either in the overall sample or in the asthmatic subgroup, suggesting that $\mathrm{OW}-\mathrm{O}$ does not produce per se any significant effect on airway obstruction. Considering lung volume indicators, the significant $\mathrm{FEV}_{1}$ and FVC decreases (as percentage of predicted), at a similar extent, in OW-O could be attributable to a limited expansion of the lungs as an effect of chest compression. ${ }^{35}$ Our findings are in agreement with the results reported by Li et al, ${ }^{36}$ who did not find any correlation between obesity and both $\mathrm{FEV}_{1}$ and FVC in a sample of obese children. Conversely, our findings differ from those of Chen et al, ${ }^{37}$ who found a negative correlation between obesity, as measured by waist circumference, and $\mathrm{FEV}_{1} / \mathrm{FVC}$, and from those of Kattan et $\mathrm{al},{ }^{15}$ reporting worse asthma control and poorer pulmonary function in female obese adolescents. In the latter paper, possible sex-related mechanisms (other than atopy and inflammation) were advocated for explaining these differences.

We found a significantly higher prevalence of subjects with allergic sensitization in OW-O (51.6\%) compared with nonobese $(37.0 \%)$. Controversial results have been reported in previous pediatric studies: allergic sensitization was not increased in OW-O, ${ }^{34}$ and atopic girls (not boys) were more frequent among subjects with high BMI. ${ }^{17}$

Exhaled NO values do not significantly differ between OW-O and subjects with a normal weight both in the whole sample and in the subgroups with asthma ever or rhinoconjunctivitis. These results are consistent with a recent study reporting no significant differences in eNO values in obese healthy children compared with nonobese controls. ${ }^{38}$ Similarly, Buchvald et $\mathrm{al}^{39}$ showed that eNO levels were not related to BMI in 4- to 17-year-old healthy children. Moreover, no significant relationship between eNO and BMI was 
found in asthmatic subjects, ${ }^{40}$ and childhood obesity was not associated with increased airway inflammation. ${ }^{41}$ Conversely, De Winter-de Groot et $\mathrm{al}^{42}$ showed that exhaled nitric oxide was positively associated with BMI in healthy adults and suggested a direct or indirect upregulation of inflammatory processes in the airways influenced by obesity. However, individual atopic status was not evaluated, and BMI was limited to the range 18 to $29 \mathrm{~kg} / \mathrm{m}^{2}$.

We found that OW-O was not associated with a significant increase in eNO in the total sample, nor in each $\mathrm{A}, \mathrm{RC}$, or nAnRC subgroup. Similarly, eNO was not significantly different among OW-O subjects in any combination of presence of asthma ever and allergic sensitization (Fig 2). A possible explanation for this result might be an information bias (eg, overdiagnosis of asthma attributable to nonspecific obesityrelated respiratory symptoms among obese children). In fact, recent meta-analyses have pointed out that some obese patients with "asthma" may have respiratory symptoms caused by obesity without objective physiological criteria for asthma $^{3}$ or an exaggerated symptom perception. ${ }^{4}$

Asthma ever, rhinoconjunctivitis, and, mainly, allergic sensitization were the only variables able to significantly increase the risk for a high eNO level, as already demonstrated in a study on a general population sample previously conducted by our group. ${ }^{16}$ Despite the fact that in the current sample no different marker of airway inflammation was available, we believe, as repeatedly reported in the literature, that allergic sensitization is one of the single most important factors affecting the association between eNO and different markers of eosinophilia. ${ }^{11,12}$ In other words, a correct interpretation of eNO values should always be based on the knowledge of the atopic status of investigated subjects.

Thus, in view of the results of the applied methods, we cannot share the hypothesis that, in overweight-obese children, systemic inflammatory mechanisms of obesity may produce an increase in eosinophilic airway inflammation, as recently suggested by Sutherland et al. ${ }^{7}$ Moreover, the lack of increased bronchial hyperresponsiveness in obese children ${ }^{17}$ further supports the hypothesis that obesity and airway inflammation are not associated conditions. Conversely, a recent report from Wood et $\mathrm{al}^{43}$ suggests that high-fat meals may augment neutrophilic airway inflammation. This controversial experimental evidence suggests that additional investigation is required for exploring common pathways possibly linking adiposity and airway inflammation.

In conclusion, our findings suggest that overweight-obesity per se does not have a significant effect on airway inflammation as measured by exhaled nitric oxide in a large sample of children and adolescents. However, our study confirms that overweight-obesity is an independent risk factor for asthma and allergic sensitization, which, in turn, are associated with airway inflammation. Thus, among older children, overweight-obesity may represent a significant burden for later health consequences.

\section{REFERENCES}

1. Asher MI, Montefort S, Björkstén B, et al; ISAAC Phase Three Study Group. Worldwide time trends in the prevalence of symptoms of asthma, allergic rhinoconjunctivitis, and eczema in childhood: ISAAC Phases One and Three repeat multicountry cross-sectional surveys. Lancet. 2006;368:733-743.

2. World Health Organization. Obesity: preventing and managing the global epidemic. WHO Technical Report Series 894. Geneva, Switzerland: WHO;2000.

3. Shore SA, Johnston RA. Obesity and asthma. Pharmacol Ther. 2006; 110:83-102.

4. Beuther DA, Sutherland ER. Overweight, obesity, and incident asthma: a meta-analysis of prospective epidemiologic studies. Am J Respir Crit Care Med. 2007;175:661-666.

5. Peroni DG, Pietrobelli A, Boner AL. Asthma and obesity in childhood: on the road ahead. Int J Obes (Lond). 2010;34:599-605.

6. Taveras EM, Rifas-Shiman SL, Camargo CA Jr, et al. Higher adiposity in infancy associated with recurrent wheeze in a prospective cohort of children. J Allergy Clin Immunol. 2008;121:1161-1166.e3.

7. Sutherland TJ, Cowan JO, Young S, et al. The association between obesity and asthma: interactions between systemic and airway inflammation. Am J Respir Crit Care Med. 2008;178:469-475.

8. Fantuzzi G. Adipose tissue, adipokines, and inflammation. J Allergy Clin Immunol. 2005;115:911-919.

9. Lim KG, Mottram C. The use of fraction of exhaled nitric oxide in pulmonary practice. Chest. 2008;133:1232-1242.

10. Piacentini GL, Bodini A, Costella S, et al. Exhaled nitric oxide and sputum eosinophil markers of inflammation in asthmatic children. Eur Respir J. 1999;13:1386-1390.

11. Strunk RC, Szefler SJ, Phillips BR, et al. Childhood Asthma Research and Education Network of the National Heart, Lung, and Blood Institute. Relationship of exhaled nitric oxide to clinical and inflammatory markers of persistent asthma in children. J Allergy Clin Immunol. 2003;112: 883-892.

12. Franklin PJ, Stick SM. The value of FeNO measurement in asthma management: the motion against FeNO to help manage childhood asthmareality bites. Paediatr Respir Rev. 2008;9:122-126.

13. Santamaria F, Montella S, De Stefano S, Sperlì F, Barbarano F, Valerio G. Relationship between exhaled nitric oxide and body mass index in children and adolescents. J Allergy Clin Immunol. 2005;116:1163-1164.

14. Leung TF, Li CY, Lam CW, et al. The relation between obesity and asthmatic airway inflammation. Pediatr Allergy Immunol. 2004;15: $344-350$.

15. Kattan M, Kumar R, Bloomberg GR, et al. Asthma control, adiposity, and adipokines among inner-city adolescents. J Allergy Clin Immunol. 2010;125:584-592.

16. Cibella F, Cuttitta G, La Grutta S, Passalacqua G, Viegi G. Factors that influence exhaled nitric oxide in Italian schoolchildren. Ann Allergy Asthma Immunol. 2008;101:407-412.

17. Schachter LM, Peat JK, Salome CM. Asthma and atopy in overweight children. Thorax. 2003;58:1031-1035.

18. Negri E, Pagano R, Decarli A, La Vecchia C. Body weight and the prevalence of chronic diseases. J Epidemiol Community Health. 1988; 42:24-29.

19. von Mutius E, Schwartz J, Neas LM, Dockery D, Weiss ST. Relation of body mass index to asthma and atopy in children: the National Health and Nutrition Examination Study III. Thorax. 2001;56:835-838.

20. Galassi C, De Sario M, Biggeri A, et al. Changes in prevalence of asthma and allergies among children and adolescents in Italy: 1994-2002. Pediatrics. 2006;117:34-42.

21. Asher MI, Keil U, Anderson HR, et al. International Study of Asthma and Allergies in Childhood (ISAAC): rationale and methods. Eur Respir J. 1995;8:483-491.

22. Position paper: Allergen standardization and skin tests. The European Academy of Allergology and Clinical Immunology. Allergy. 1993;48 (14 Suppl):48-82. 
23. Gilliland FD, Berhane K, Islam T, et al. Obesity and the risk of newly diagnosed asthma in school-age children. Am J Epidemiol. 2003;158: $406-415$.

24. Miller MR, Hankinson J, Brusasco V, et al; ATS/ERS Task Force. Standardisation of spirometry. Eur Respir J. 2005;26:319-338.

25. Pistelli F, Bottai M, Carrozzi L, et al. Reference equations for spirometry from a general population sample in central Italy. Respir Med. 2007; 101:814-825.

26. ATS/ERS recommendations for standardized procedures for the online and offline measurement of exhaled lower respiratory nitric oxide and nasal nitric oxide, 2005. Am J Respir Crit Care Med. 2005;171:912-930.

27. Jöbsis Q, Schellekens SL, Kroesbergen A, Hop WC, de Jongste JC. Sampling of exhaled nitric oxide in children: end-expiratory plateau, balloon and tidal breathing methods compared. Eur Respir J. 1999;13: $1406-1410$.

28. Dietz WH, Robinson TN. Use of the body mass index (BMI) as a measure of overweight in children and adolescents. J Pediatr. 1998;132: 191-193.

29. Cole TJ, Bellizzi MC, Flegal KM, Dietz WH. Establishing a standard definition for child overweight and obesity worldwide: international survey. BMJ. 2000;320:1240-1243.

30. Himes JH, Dietz WH. Guidelines for overweight in adolescent preventive services: recommendations from an expert committee. Am J Clin Nutr. 1994;59:307-316.

31. Guh DP, Zhang W, Bansback N, Amarsi Z, Birmingham CL, Anis AH. The incidence of co-morbidities related to obesity and overweight: a systematic review and meta-analysis. BMC Public Health. 2009;9:88.

32. To T, Vydykhan TN, Dell S, Tassoudji M, Harris JK. Is obesity associated with asthma in young children? J Pediatr 2004;144:146-147.

33. Castro-Rodríguez JA, Holberg CJ, Morgan WJ, Wright AL, Martinez FD. Increased incidence of asthmalike symptoms in girls who become overweight or obese during the school years. Am J Respir Crit Care Med. 2001;163:1344-1349.

34. Beuther DA, Weiss ST, Sutherland ER. Obesity and asthma. Am J Respir Crit Care Med. 2006;174:112-119.
35. Nicolacakis K, Skowronski ME, Coreno AJ, et al. Observations on the physiological interactions between obesity and asthma. J Appl Physiol. 2008;105:1533-1541.

36. Li AM, Chan D, Wong E, et al. The effects of obesity on pulmonary function. Arch Dis Child. 2003;88:361-363.

37. Chen Y, Rennie D, Cormier Y, Dosman JA. Waist circumference associated with pulmonary function in children. Pediatr Pulmonol. 2009;44:216-221.

38. Santamaria F, Montella S, De Stefano S, et al. Asthma, atopy, and airway inflammation in obese children. J Allergy Clin Immunol. 2007; 120:965-967.

39. Buchvald F, Baraldi E, Carraro S, et al. Measurements of exhaled nitric oxide in healthy subjects age 4 to 17 years. J Allergy Clin Immunol. 2005; 115:1130-1136.

40. Kazaks A, Uriu-Adams JY, Stern JS, Albertson TE. No significant relationship between exhaled nitric oxide and body mass index in people with asthma. J Allergy Clin Immunol. 2005;116:929-930.

41. Verhulst SL, Aerts L, Jacobs S, et al. Sleep-disordered breathing, obesity, and airway inflammation in children and adolescents. Chest. 2008; 134:1169-1175.

42. De Winter-de Groot KM, Van der Ent CK, Prins I, Tersmette JM, Uiterwaal CS. Exhaled nitric oxide: the missing link between asthma and obesity? J Allergy Clin Immunol. 2005;115:419-420.

43. Wood LG, Garg ML, Gibson PG. A high-fat challenge increases air way inflammation and impairs bronchodilator recovery in asthma. J Allergy Clin Immunol. 2011;127:1133-1140.

Requests for reprints should be sent to:

Fabio Cibella, MD

Consiglio Nazionale delle Ricerche-Istituto di Biomedicina e Immunologia Molecolare "A. Monroy"

Via Ugo La Malfa, 153

I 90146 Palermo, Italy

E-mail: cibella@ibim.cnr.it 